\title{
DIFICULDADES DE APRENDIZAGEM NO CONTEXTO ESCOLAR: possíveis estratégias didáticas e de intervenção
}

\author{
Wildson Cardoso Assunção' \\ José Carlos de Freitas²
}

\section{RESUMO}

O objetivo deste artigo é descrever e refletir sobre algumas das dificuldades de aprendizagem presentes no contexto escolar e, através disso, pontuar algumas das estratégias didáticas e de intervenção que podem ser utilizadas pelos professores. Trata-se um estudo teórico, na modalidade de revisão narrativa da literatura. Buscamos reunir algumas das discussões e propostas atuais que se basearam em questionamentos sobre inserção da Psicologia na Educação e tipos de estratégias didáticas utilizadas nas determinadas dificuldades de aprendizagem. Os achados mostram que existem constantes diálogos entre a Psicologia e a Educação, havendo possibilidades de trabalhar dificuldades de aprendizagem com uso de recursos que podem se adequar à estrutura das escolas, com intuito de facilitar o processo de aprendizagem.

Palavras-chave: Dificuldades de Aprendizagem. Transtornos de Aprendizagem. Estratégias Didáticas.

\section{LEARNING DIFFICULTIES IN THE SCHOOL CONTEXT: possible teaching and intervention strategies}

\begin{abstract}
The aim of this article is to describe and reflect on some of the learning difficulties present in the school context and, therefore, to highlight some of the didactic and intervention strategies that can be used by teachers. It is a theoretical study, in the modality of narrative review of the literature. We sought to gather some of the current discussions and proposals that were based on questions about the insertion

\footnotetext{
1 Graduado em Psicologia pelo Centro Universitário UnirG - UnirG; Especialista em Psicologia Organizacional e do Trabalho pela Faculdade de Ciências Sociais Aplicadas de Marabá FACIMAB; Especialista em Psicologia Cognitivo-Comportamental. Atualmente é Psicólogo Clínico e da Saúde da Associação de Pais e Amigos dos Excepcionais de Porto Nacional/TO. Orcid iD: https://orcid.org/0000-0001-9241-1082. E-mail: wildson.se@outlook.com

2 Graduado em Filosofia pela Universidade Estadual do Oeste do Paraná, Especialista em Língua Portuguesa pela Universidade Salgado de Oliveira, Mestre em Letras pela Universidade Federal Fluminense - UFF. Aluno especial do Doutorado em Ética e Filosofia Política da Universidade Federal de Goiás - UFG. Atualmente é professor efetivo da Universidade de Gurupi - UnirG, Tocantins. Orcid iD: https://orcid.org/0000-0001-7945-1557. Email: lapisvia@gmail.com
} 
of Psychology in Education and types of didactic strategies used in certain learning difficulties. The findings show that there are constant dialogues between Psychology and Education, and there are possibilities of working with learning difficulties using resources that can be adapted to the structure of schools, in order to facilitate the learning process.

Keywords: Learning Difficulties. Learning Disorders. Didactic Strategies.

\section{DIFICULTADES DE APRENDIZAJE EN EL CONTEXTO ESCOLAR: posibles estrategias didácticas y de intervención}

\section{RESUMEN}

El objetivo de este artículo es describir y reflexionar sobre algunas de las dificultades de aprendizaje presentes en el contexto escolar y, por lo tanto, resaltar algunas de las estrategias didácticas y de intervención que pueden utilizar los profesores. Es un estudio teórico, en la modalidad de revisión narrativa de la literatura. Tratamos de reunir algunas de las discusiones y propuestas actuales que se basaron en preguntas sobre la inserción de la Psicología en la Educación y los tipos de estrategias didácticas utilizadas en ciertas dificultades de aprendizaje. Los hallazgos muestran que hay diálogos constantes entre psicología y educación, y hay posibilidades de trabajar con dificultades de aprendizaje utilizando recursos que pueden adaptarse a la estructura de las escuelas, para facilitar el proceso de aprendizaje.

Palabras claves: Dificultades de Aprendizaje. Trastornos de Aprendizaje. Estrategias Didácticas.

\section{INTRODUÇÃO}

Dificuldades de aprendizagem são temáticas de diversos debates da Psicologia e da Educação. Na concepção de Almeida, et al. (2016) os conceitos de dificuldades de aprendizagem são amplos e envolvem um conjunto de diferentes fatores que interferem direta ou indiretamente na aprendizagem.

O termo "dificuldades de aprendizagem" foi idealizado em 1962 por Samuel Alexander Kirk (1904 - 1996) e se refere a dificuldades que englobam diversos fatores, provocando ciclos falhos ou reduzidos nos processos de aprendizagem (REID; LIENEMANN; HAGAMAN, 2013).

Semkiw e Ansai (2014) afirmam que esse termo está constantemente presente nas discussões dos profissionais da educação nas escolas e por psicólogos. Para os autores, essas dificulades se dão pelo fato de o aluno 
não alcançar o conhecimento desejado, ainda que não possua nenhuma deficiência evidente, e estabelecer ações de intervenção.

É necessário considerar também, os transtornos de aprendizagem que, por definição, são disfunções orgânicas relacionadas à aquisição e uso de informações, dentre elas a escrita, a leitura, a capacidade de leitura e lógico-matemática (ALVES; NAKANO, 2015).

Com o recente surgimento de disciplinas como as Ciências Cognitivas, que estuda cognição e fatores relacionados ao cérebro (OLIVEIRA, 2014), foi possível estabelecer alguns dos fatores que interferem na capacidade de aprendizagem, seja ela orgânica ou devido a outros fatores.

Um estudo de Reid, Lienemann e Hagaman (2013) aponta que dificuldades de aprendizagem levam a um desenvolvimento mais lento das habilidades acadêmicas e, consequentemente, impede novas aprendizagens, gerando o ciclo repetido de "fracasso".

Ferreira e Horta (2014) concordam com esse ponto de vista e acrescentam que essas dificuldades, especialmente, as dificuldades de leitura, consistem em um dos principais obstáculos para um bom desempenho escolar e que se não houver alguma intervenção específica, haverá sérios prejuízos inclusive em outros aspectos da vida do aluno.

Em relação ao surgimento das dificuldades de aprendizagem, compreende-se que pode haver variações de acordo com a idade, mas grande parte das pesquisas sugere que essas dificuldades se manifestam, especialmente, nos anos escolares iniciais.

No Brasil, as dificuldades escolares atingem cerca de $5 \%$ da população escolar (BRASIL, 2014). Pode parecer um número pequeno, no entanto, ao analisarmos algumas das causas e características que podem levar às dificuldades de aprendizagem, percebemos a presença dos seguintes fatores: Problemas visuais, auditivos, deficiência motora, deficiência intelectual, problemas emocionais das mais diversas naturezas, mudança de ambiente, fatores socioeconômicos (CORTIELLA et al., 2014).

Vale lembrar que de acordo com outros estudos, há dados que sugerem que há um adicional de aproximadamente $15 \%$ ou mais de alunos 
que poderiam ter dificuldades na aprendizagem, mas que não teriam sido avaliados. Essas dificuldades poderiam ou não estar ligadas a transtornos da atenção, linguagem ou do comportamento. Isso atinge a aprendizagem de diferentes formas em cada pessoa, dificultando uma avaliação inicial por parte do professor, consequentemente, não trabalhando o aluno de uma maneira mais adequada.

Em relação a isso, cabe mencionar sobre um estudo de Tabile e Jacometo de 2017 que mostrou que, na maioria dos casos, o professor é, ou deveria ser o primeiro a identificar dificuldades na criança, antes mesmo dos pais ou familiares.

Existem pesquisas que apontam essas e outras vulnerabilidades como correlacionadas a outras queixas escolares, aumentando mais ainda a probabilidade de comportamentos deficitários no contexto escolar e problemas emocionais fora dele (MARTURANO; ELIAS, 2016).

Inácio, Oliveira e Mariano (2017) sugerem a aplicação de estratégias diversificadas no processo de aprendizagem. Conforme as autoras, tais estratégias facilitam a aquisição de conhecimento, associando e armazenamento o uso de informações e conceituação prática daquilo que foi aprendido.

Considerando que a escola tem um importante papel no desenvolvimento social e cognitivo do indivíduo, cabe ao professor ter a sensibilidade e competência de identificar evidências de que o aluno possui dificuldades significativas em relação à maioria, podendo assim, encaminhálo a um psicólogo ou instituição que tenha um psicólogo.

Infelizmente, a educação no Brasil ainda não tem a estrutura necessária para lidar sozinha com todos esses fatores, com isso, percebe-se como seria útil uma psicologia que atuasse dentro das escolas. A Psicologia Escolar ou Educacional já existe e é uma das áreas de especialização reconhecidas pelo Conselho Federal de Psicologia - CFP, através da resolução 013/2007. 
A proposta de inserção do psicólogo nas escolas vem sendo discutida há bastante tempo no Senado, no entanto, ainda não há nada aprovado por lei.

Além do trabalho com os alunos, a intervenção da psicologia nas escolas possibilita o desenvolvimento de ações com pais e/ou responsáveis e eventualmente outras áreas da equipe escolar. No caso dos professores é possível também pontuar e indicar estratégias didáticas que possam facilitar o trabalho com os alunos.

Mesmo não havendo regulamentações específicas que garantam o trabalho da psicologia nas escolas de forma integral, há discussões que nos levaram aos seguintes questionamentos: "É possível, com os recursos e meios atuais, utilizar a psicologia na educação?" "Que tipo de estratégias didáticas podem ser aplicadas em dificuldades de aprendizagem?".

Diante dessa realidade, o presente estudo teve como objetivo descrever e refletir sobre algumas das dificuldades de aprendizagem presentes no contexto escolar e, através disso, pontuar algumas das estratégias didáticas e de intervenção que podem ser utilizadas pelos professores.

O método de busca ocorreu por meio de revisão narrativa da literatura, com análise de dados descritiva e qualitativa. De acordo com Ănima (2014), a seleção do conteúdo nessa modalidade possibilita um estudo sobre um conceito específico ou numa área específica em que a pesquisa é resumida, analisada, e as conclusões totais são extraídas. Essa metodologia também possibilita a consulta em diversas bases de dados sem estabelecer critérios de busca definidos, sistemáticos ou replicáveis.

\section{BREVE HISTÓRICO SOBRE O ESTUDO DA APRENDIZAGEM}

A palavra "Aprender" nos remete ao sentido de adquirir conhecimento teórico ou empírico sobre algo ou alguma coisa. Segundo Natel, et al. (2013), o conceito de aprendizagem como o conhecemos, bem como seu estudo, tiveram sua origem há muito tempo, mais precisamente, na filosofia de Sócrates (469/399 d.C), através do pressuposto da 
necessidade de autoconhecimento e nas afirmações Platônicas relacionadas à importância do saber.

A própria Filosofia possui em sua etimologia, algo que nos direciona à aprendizagem, seus radicais: "Philo" significa Amizade e "Sophia" significa Saber, em outras palavras, Filosofia significa "Amizade pelo saber" (SILVA, 2014).

Com os avanços científicos, uma série de disciplinas relacionadas às Ciências Cognitivas possibilitaram investigações mais precisas sobre como a mente interpretava e adquiria a aprendizagem (OLIVEIRA, 2014). Através dessas novas descobertas, foi possível entender alguns fatores chave que norteariam intervenções eficazes no campo da psicologia e da educação.

Essas investigações científicas surgiram através de estudos empíricos da Psicologia com base no aprendizado por experiência. Essa nova perspectiva considerou uma série de associações desde o nascimento da pessoa, até o que se entende de habilidades para aquisição de conhecimento (GIUSTA, 2013). Dentro dessa perspectiva, a aprendizagem é entendida como um processo psicológico, intermediado pela subjetividade.

Teóricos como Jean William Fritz Piaget (1896-1980) e Lev Semyonovich Vygotsky (1896-1934) estabeleceram estudos relacionados à aprendizagem e cognição, além da maturação intelectual (CASTRO; TREDEZINI, 2014). Esses dois teóricos realizaram importantes contribuições nos campos da Psicologia e Educação, sendo os nomes mais reconhecidos no tocante à aprendizagem.

Burrhus Frederic Skinner (1904-1990) também realizou estudos relacionados à aprendizagem, através de explicações comportamentais, em que o comportamento seria aprendido e motivado pelo ambiente e por forças internas e externas à pessoa (FEIST, FEIST; ROBERTS, 2015). A teoria de Skinner é baseada na ideia de que a aprendizagem é uma função da mudança de comportamento.

Outro grande teórico que trouxe contribuições para o estudo da aprendizagem foi Albert Bandura, o qual apontou que as pessoas aprendem a responder de forma subjetiva, observando outras pessoas, que seriam os 
modelos (PAPALIA; FELDMAN, 2013). Bandura foi um dos primeiros teóricos a estabelecer os processos cognitivos, como pensamento e raciocínio, iniciando estudos denominados de aprendizagem social-cognitiva.

A partir desses pressupostos, observou-se que boa parte das discussões relacionadas à aprendizagem tenta estabelecer causas e princípios que ajudam na compreensão de dificuldades ou agravos na aprendizagem.

De acordo com Bezerra (2014) mesmo as escolas se empenhando para proporcionar mais qualidade de ensino, ainda existe dificuldade em relação à aprendizagem de alguns alunos, que supostamente possuem dificuldades acentuadas, sendo comuns divergências em torno dessas discussões, algumas enfatizando $o$ ambiente e outras enfatizando características pessoais.

\section{DIFICULDADES DE APRENDIZAGEM NO CONTEXTO ESCOLAR}

O ambiente escolar é um dos primeiros níveis de interação social a qual uma criança se integra. Bolsoni-Silva, et al. (2013) afirmam que esse ambiente tem sido uma área estratégica de estudos, no tocante às práticas educativas.

Com isso, Monteiro e Silva (2015) chamam a atenção para a importância de se considerar a estrutura adequada na escola, pois a estrutura está diretamente ligada com as possibilidades de êxito no ensinoaprendizagem.

Para os autores, nem sempre a escola possui uma estrutura adequada, apesar de ser um espaço importante. Muito disso ocorre devido a má administração de recursos e má administração política.

Nunes et al. (2013) observam escolas com condições precárias e condições de má formação docente. Esses problemas são sérios e podem gerar prejuízos enormes na educação e em diversos outros aspectos.

Em estudos mencionados por Barbosa (2015) consta que história das dificuldades de aprendizagem existe mesmo antes desse termo ter sido conceituado, de acordo com o autor, na década de 90 houve interação 
entre diversos profissionais e pesquisadores para tentar compreender as dificuldades de aprendizagem.

Quase 30 anos depois, mesmo com estudos dentro dessa temática, as dificuldades de aprendizagem ainda não parecem esclarecidas pelas pessoas, tampouco parte integral em algumas formações docentes.

Considerando o ambiente escolar como mantenedor de vínculos sociais, pressupõe-se que análises e intervenções ocorram diariamente com os recursos que esse ambiente possibilitar, levando em conta aspectos que vão além da Educação (SEMKIW; ANSAI, 2014).

Na pior das hipóteses, dificuldades de aprendizagem não trabalhadas levam ao "Fracasso Escolar". Bezerra (2014) enfatiza que essa nomenclatura é inadequada, por se tratar do resultado de um conjunto de esforço de professores e alunos que não obteve os resultados esperados, além de provocar a ideia de exclusão, incapacidade e reprovação.

Pozzobon, Mahendra e Marin (2017) sugerem que essa nomenclatura seja revista, por possibilitar conotações pejorativas aos alunos, causando prejuízos secundários sobre o desempenho escolar e social, que já estariam sendo prejudicados devido às dificuldades.

Marturano e Elias (2016) falam da importância de levar em conta fatores ambientais como forma de melhor compreensão dos problemas emocionais e comportamentais das pessoas que teriam ou poderiam desenvolver alguma dificuldade na aprendizagem.

Nunes et al. (2013, p.65) concordam e dão exemplos de escolas públicas "as quais não possuem materiais adequados para oferecer aos alunos e professores desmotivados que não disponibilizam tempo de planejamento, não dão conta de envolver a comunidade".

Esse ponto de vista parece ser generalizado, tendo em vista que a educação pública no Brasil é assegurada pela Constituição Da República Federativa do Brasil de 1988, em seu artigo $6^{\circ}$ que estabelece que "São direitos sociais a educação, a saúde, a alimentação, o trabalho, a moradia (...)". 
Apesar das dificuldades gerais na educação pública, há sempre notícias nos portais jornalísticos que divulgam o sucesso das escolas ou de alunos em atividades como olimpíadas de conhecimento, Vestibulares, Exame Nacional do Ensino Médio - ENEM, debates e concursos com fins educacionais, dessa forma, não é cabível situar apenas a estrutura escolar ou motivação docente.

Bolsoni-Silva et al. (2013) afirmam que existe complexidade no ambiente escolar que envolve o ensino formal e o desenvolvimento dos alunos. De certa forma, o contexto escolar atual também tem se tornado ambiente de aprendizagem de questões que deveriam ser ensinadas ainda no ambiente familiar e em anos anteriores a inserção na escola.

O Art. 205 da constituição estabelece que a educação é um direito de todos e dever do Estado e da família, apesar de Estado vir antes de família, uma interpretação correta (pelo menos de um ponto de vista prático) seria que a família educasse assuntos como moral, valores e etc. e que a escola cuidasse da educação formal junto das disciplinas acadêmicas.

Na concepção de Benato (2014), a escola e a família formam uma rede socializadora e educativa, cada uma com seu papel estabelecido, que se complementaria, sendo que ambas formam os indivíduos através da educação e do desenvolvimento de habilidades sociais e intelectuais para a sociedade.

Constantemente na literatura podem-se encontrar eixos temáticos associando as dificuldades escolares na aprendizagem a transtornos de aprendizagem ou dificuldades mais acentuadas na compreensão sobre o conteúdo ensinado, e também na estratégia didática que o professor utiliza (BOLSONI-SILVA et al., 2013).

De qualquer forma, é importante que os profissionais da educação saibam diferenciar dificuldades de aprendizagem e transtornos de aprendizagem. As dificuldades abrangeriam problemas passíveis de modificação, enquanto os transtornos estariam condicionados a fatores orgânicos, também passíveis de modificação, no entanto, demandando 
outros tipos de estratégias e também acompanhamento psicológico especializado (PIMENTEL; LARA, 2017).

De acordo com Coelho (2015), as dificuldades de aprendizagem apresentadas podem ocorrer principalmente devido a problemas no desenvolvimento, sendo importante um olhar psicopedagógico também no contexto familiar, uma vez que os relacionamentos familiares do meio do aluno podem causar danos à aprendizagem.

Através do exposto é possível estabelecer uma relação entre contexto escolar e aprendizagem, com a participação da família. E em caso de falhas no meio desse processo, a escola teria de mediar ou mesmo encaminhar os casos para profissionais especializados, a fim de reduzir danos ou evitá-los (SEMKIW; ANSAI, 2014).

\section{BREVE CONCEITO DOS TRANSTORNOS DE APRENDIZAGEM MAIS COMUNS}

Também chamados de distúrbios da aprendizagem, Mano e Marchello (2015) mencionam que dificuldades de aprendizagem estão relacionadas a diversos transtornos que afetam determinadas áreas da aprendizagem, como matemática, escrita e linguagem. Os autores também fazem referência à terminologia em inglês "learnig disabilities" que é traduzido para o português literalmente como "incapacidades de aprendizagem", sendo considerado no Brasil como distúrbios de aprendizagem.

Existe uma série de distúrbios e variações, podendo haver comorbidade com outros transtornos ou déficits, que potencializam os prejuízos na vida do indivíduo. De acordo com Tabaquim (2016, p.358) "transtornos de aprendizagem são alterações no sistema nervoso central". Existe um aumento claro nos estudos dos transtornos de aprendizagem, especialmente em transtornos que causam déficits na linguagem, como a dislexia, e nos processos cognitivos não-verbais.

Segundo Damasceno e Gomes (2014), o comportamento de uma criança com transtornos se difere da maioria das outras crianças, por não alcançarem os resultados estabelecidos, consequentemente, levando à desmotivação e outras perdas emocionais. 
Em relação ao transtorno, percebe-se queixa de profissionais quanto ao diagnóstico e aos sintomas, sendo comum a falta de profissional especializado que possa sanar essas dúvidas (LIRA, 2014).

Apesar de relatos desses transtornos mais específicos serem comuns, existe falta de entendimento quanto aos critérios diagnósticos nas formações docentes. Essa dificuldade pode levar os professores a associarem os alunos, a partir de alguns sintomas que eles achem parecido com algum transtorno, antes mesmo da avaliação de um especialista, causando a "patologização da educação" (SIGNOR, 2015).

O Manual de Diagnóstico e Estatístico de Transtornos Mentais, conhecido pela sigla DSM (2014), em sua quinta edição caracteriza alguns dos transtornos de aprendizagem mais comuns, dentre eles, resumidamente: a Dislexia, que causa dificuldades no reconhecimento de palavras; Disgrafia, que causa dificuldades na aprendizagem ortográfica; Discalculia, que é a dificuldade com o raciocínio matemático; Dislalia, que é um distúrbio que afeta a fala.

A dislexia é uma desordem neurobiológica, queixas e relatos sobre dislexia estão entre as mais frequentes no contexto escolar, sendo muitas vezes associadas a outras dificuldades dos alunos.

Santos (2016) orienta como o professor deve ajudar em casos de dislexia, antes do possível encaminhamento, através de dicas de organização, reforço nos acertos, utilização de linguagem clara, dar mais tempo para a realização das atividades com peças de montar, e claro, um bom vínculo professor-aluno.

A disgrafia, por sua vez, é um distúrbio que se caracteriza por uma leve desordem motora, levando a pessoa a produzir uma escrita confusa, consequentemente, com mais erros ortográficos (MAGALHÃES, 2015).

Essa autora incentiva o treino e metodologias ativas como jogos, brincadeiras, exercícios de caligrafia, tipos de canetas, e orientação quanto ao papel da família nesses reforços.

Em estudos mencionados por Pimentel e Lara (2017) consta que a discalculia é um pouco mais rara e de difícil diagnóstico. A discauculia 
envolve problemas no processamento de informações, especialmente as numéricas, com aprendizagem mais lenta ou inexistente ao realizar cálculos precisos ou exercícios que envolvam formulação de ideias com números.

Ferdig (2013) menciona jogos mentais, como o "Cognifit", que é um jogo conhecido por profissinais da psicologia e da educação. Trata-se de jogos que envolvem cognição e estratégias de aprendizagem com números.

A dislalia é um distúrbio que também pode estar associado a ambientes aversivos ou experiências subjetivas aversivas. De acordo com Sánchez (2016) a dislalia se caracteriza como um distúrbio na articulação de fonemas, ou por ausência deles, alterando o som das palavras.

Ferreira (2014) afirma que existem duas classificações para dislalia, sendo a dislalia fonológica, que envolve processo de acuidade auditiva e a dislalia fonética, que interfere nas articulações das palavras e falta de coordenação motora.

\section{PROFESSOR-ALUNO: A INTER-RELAÇÃO DA APRENDIZAGEM}

Entende-se por inter-relação uma relação em comum entre duas ou mais coisas. O processo de inter-relação é natural no contexto escolar, pois sem isso não há ensino, socialização, tampouco aprendizagem.

No contexto escolar das dificuldades de aprendizagem, a interrelação que ocorre entre professor-aluno possibilita aprendizagem e superação de eventuais dificuldades. Silva (2016a) apresenta que a interrelação é concebida como amigável e de respeito mútuo, de forma que isso facilite o processo de ensino aprendizagem, sem que os papeis sejam abandonados.

Mattos et al. (2013) concordam com esse ponto de vista e acrescentam que o discurso dos alunos deve ser levado em consideração em meio ao processo de aprendizagem, de um ponto de vista construtivo e horizontalmente hierárquico.

A assimilação é o processo pós-aprendizagem em que aluno percebe como usar aquela informação, naquele ou em outros contextos, por dedução, analogia ou por reflexo. Durante o processo de assimilação, uma 
característica essencial na inter-relação é a afetividade, que pode auxiliar como aspecto motivacional e reforçador (FATEL, 2016).

Seguindo essa mesma linha de raciocínio Silva (2016b) afirma que a relação professor-aluno é similar à relação ensino-aprendizagem. A partir desse pressuposto, percebe-se o quanto é necessário haver contextos específicos para a aprendizagem e, consequentemente, trabalhar dificuldades de aprendizagem.

Dessa forma Mattos et al. (2013) recomendam que nesse processo sejam utilizadas novas experiências (diferentes da rotina), o uso de metodologias alternativas (que pode ser criada ou incentivada pelos próprios alunos), aulas livres que possibilitem a discussão de um tema atual, de interesse de todos.

Compreender a postura ética do educador, também envolve uma questão de inter-relação. Vale lembrar que Freitas e Silva (2016) enfatizam que existe diferença entre ética e discurso ético, no entanto, não existe educação sem ética, sendo esses fatores inseparáveis.

O papel da escola na sociedade envolve responsabilidades e deveres éticos, apesar de tudo, nesse mesmo ambiente, alguns alunos não conseguem alcançar as expectativas e metas escolares, esse acontecimento é encontrado na literatura como o "fracasso escolar ou dificuldades de aprendizagem".

A questão do fracasso escolar pode repercutir na vida da pessoa, gerando impactos mesmo fora da escola. Dessa forma, Silva (2016a) considera que os aspectos éticos envolvem uma amplitude que vão também além da escola, devendo ser reconsiderados e repensados antes de quaisquer posicionamentos que possam interferir negativamente na vida do aluno.

A responsabilidade ética social proporciona qualidade no ensino e na assimilação dos alunos sobre o conteúdo ensinado. Mattos et al. (2013) estabelecem sobre a questão da necessidade ética do cuidado e sobre a importância do diálogo moral na educação. 


\section{ESTRATÉGIAS DIDÁTICAS}

Conforme a literatura, lidar com as questões de dificuldades de aprendizagem ou transtornos de aprendizagem, apesar de ser discutido, ainda é uma temática pouco repercutida na prática, em algumas regiões, por se tratar de questões multifatoriais e que envolvem assuntos que não estão na grade de formação de uma grande parcela dos educadores (GIMENEZ, 2015).

Estratégias didáticas ou estratégias de ensino-aprendizagem são vistas na literatura como recursos que devem se adequar ao ambiente e às necessidades de cada aluno. Paiva e Silva (2015) afirmam a importância dessas estratégias no processo de ensino-aprendizagem, de acordo com essa concepção essas estratégias deveriam abranger as condições reais da sala de aula. Ainda de acordo com essas autoras, as estratégias utilizadas pelo professor, além de facilitar o processo de aprendizagem, tornam as aulas dinâmicas, interessantes e participativas.

Mazzioni (2013) afirma que, historicamente, a palavra estratégia era vinculada aos planejamentos militares, especialmente no tocante à guerra. O termo "estratégias de ensino" se refere justamente à prática do planejamento, realizado a partir das demandas em sala de aula.

Dessa forma, entende-se por estratégias didáticas, um sinônimo de estratégias de ensino, como sendo um conjunto de técnicas e planejamentos que visam realizar atividades organizadas, focadas no ensino e na compreensão dos alunos por esse meio. Felcher, Dias e Bierhalz (2015) relacionam essas estratégias à interdisciplinaridade, que é um conceito amplamente discutido e que traz diversas possibilidades de atuação.

Dentre possíveis estratégias didáticas, essas autoras trabalharam a construção de maquetes virtuais e físicas, sendo uma atividade que possibilita aprendizagem de forma interdisciplinar e que reflete sobre questões ambientais, envolvendo os alunos de forma educativa.

Paiva e Silva (2015) destacam que a fase de planejamento é extremamente importante e deve ser de acordo com a realidade da escola e sala de aula. O contexto escolar deve oferecer recursos para que tais 
estratégias sejam postas em práticas, esses recursos variam desde livros didáticos, o ambiente em que a aula acontece, recursos materiais e participação familiar, em alguns casos.

Mazzioni (2013) destaca algumas das possíveis estratégias didáticas, que poderiam ser entendidas como facilitadoras também no contexto escolar, dentre as estratégias citadas estão: aula expositiva/dialogada, Estudo de texto (leitura), Tempestade de ideias (Brainstorming), Grupo de verbalização e de observação (GO/GV), Dramatização, Role-Play Desempenho de papéis, e etc.

Para Paiva e Silva (2015), além de recursos materiais e funcionais é necessário o uso da criatividade por parte dos professores, em meio aos recursos empregados no processo de ensino e aprendizagem, para isso, as autoras afirmam ser indispensável o planejamento apoiado no contexto de cada aluno.

Alves (2017) afirma que essas estratégias têm sido desenvolvidas por psicólogos e profissionais da educação. A autora também discorre sobre estratégias em relação ao vocabulário, dentre elas o uso de fotos e desenhos, objetos reais, exemplos, definições, mapas conceituais e relação de palavras.

Na perspectiva de Teixeira e Alliprandini (2013), a intervenção através do uso de estratégias na aprendizagem é significativa para os alunos que apresentam dificuldades, ainda que leves, pois é preciso considerar que o ambiente escolar é um ambiente de aprendizagem e que deve se adequar às necessidades dos alunos.

A questão da subjetividade é muito importante em meio às estratégias no processo de aprendizagem, sendo que cada aluno se adapta e aprende de forma diferente, sendo um fenômeno complexo, mas estudável. Ferreira e Horta (2014) enfatizam os métodos e estratégias ativas e participativas que contribuam para que $\mathrm{o}$ aluno mantenha a consciência de que se desenvolva, em termos de competência, com autonomia.

Compreende-se que a autonomia no processo de aprendizagem facilita o trabalho do professor e deve ser incentivada, justamente através 
das metodologias de estratégias didáticas, tais estratégias funcionam como uma via de mão dupla, em que há a aprendizagem e um tipo de plasticidade para novas informações.

\section{ESTRATÉGIAS INTERVENÇÃO}

Estratégias didáticas já são intervenções, as demais estratégias de intervenção se dão pela necessidade de acompanhamentos, que muitas vezes, não podem ser realizados dentro das escolas (quando não há o serviço especializado dentro da escola), esse serviço existe na rede pública e privada e promove assistência didática, (neuro)psicológica e de convívio social. Essa rede pode ser acionada também em caso de necessidades extraescolar, na família.

A literatura mostra que maioria dos casos encaminhados de escola a serviços especializados tem mais relação com dificuldades de aprendizagem de fala, escrita e memória (MAZZAROTTO et al., 2016) esses casos podem acontecer devido a uma série de outros fatores, que vão de maus-tratos, negligência, a abusos das mais variadas formas.

De acordo com a assistência social de Alagoas (2017), existem demandas que atingem o ambiente familiar, causando vulnerabilidade e/ou risco social, sendo necessária uma instituição para garantir ao usuário o acesso à renda, serviços, programas e projetos. Dessa forma, pode haver solicitação por parte da escola, para que haja esse acesso e intervenção.

A vulnerabilidade seja ela psicológica, socioeconomica, sexual e etc. produz um sério dano à sociedade e coloca em risco uma série de direitos fundamentais que devem ser protegidos e prevenidos.

É necessário que a escola saiba pontuar as ações necessárias para as estratégias de ensino e a análise dos casos que necessitem de acompanhamento especializado ou acompanhamento familiar. Casos em que algum fator que esteja perturbando o aprendizado do aluno, prejudicando a capacidade plena e o direito à educação integral. Trabalhar isso também diminuiria os índices de exclusão (GUSSI, 2016). 
Seguindo essa mesma perspectiva, Gimenez (2015) afirma que apesar de existirem essas redes de apoio, ainda existem diversos encaminhamentos equivocados de alunos que supostamente tinham alguma dificuldade mais acentuada, gerando uma visão de que existe incapacidade do aluno de responder ao longo do tempo, de acordo com as novas tarefas, dando uma ideia de que essa incapacidade é culpa somente do aluno.

Reis e Pezzi (2016) refletem que o encaminhamento tem sido uma estratégia de intervenção, especialmente se tratando de dificuldades de aprendizagem, sendo esses casos mais comuns do que queixas mais complexas. No entanto, as autoras chamam a atenção para esses encaminhamentos que seriam feitos por professores que não tinham uma compreensão clara ou não teriam um diagnóstico preciso da possível dificuldade ou distúrbio.

Da mesma forma Mazzarotto et al. (2016) afirmam que são recorrentes as queixas sobre crianças que não satisfaziam a apropriação da linguagem e escrita. Esses encaminhamentos para serviços especializados seriam frequentes e motivados por queixas de dificuldades na aprendizagem.

Reis e Pezzi (2016) chamam a atenção para os profissionais tomem conhecimento da real situação que gera dificuldades de aprendizagem para que haja intervenção efetiva.

É importante que dentro do planejamento pedagógico da escola tenha espaço para formações continuadas voltadas às demandas mais comuns dentro da escola, é importante que haja diálogo com a psicologia, como palestras, roda de conversa, seminários e estudos de caso.

Independente desse plano, Gussi (2016) orienta aos professores que reflita e identifiquem a natureza dos problemas, com auxilio de outros profissionais, se necessário, para que possam sugerir e agir conforme as demandas levantadas. 


\section{PERSPECTIVAS DE ATUAÇÃO FRENTE AOS TRANSTORNOS DE APRENDIZAGEM}

Conforme visto na literatura, dificuldades de aprendizagem são obstáculos que podem ser superados desde que haja uma conjugação de esforços escolares e extraescolares em prol do desenvolvimento do aluno.

No caso da dislexia, para que haja intervenções adequadas, no tempo adequado é preciso utilizar os recursos presentes na fase escolar dos primeiros anos, pois nessa fase, é mais fácil identificar e, possivelmente, diagnosticar (BARBOSA, 2014).

A dislalia, por sua vez, pode ser mais fácil de perceber, é necessário que haja acompanhamento fonoaudiológico, no qual serão realizados procedimentos que evitem o agravo da situação (FERREIRA, 2014).

Assim como a dislalia, Barbosa (2014) afirma que a dislexia também pode ser identificada precocemente, especialmente, quando se conta com auxílio de outros profissionais.

As perspectivas de atuação precisam ser entendidas de um ponto de vista amplo, que enfoquem também as capacidades subjetivas de desenvolvimento. Ferrari (2013) alerta que precisamos entender a aquisição da linguagem e da escrita como um processo que é concebido em diferentes fases, não havendo um prazo definido para que a pessoa alcance um próximo nível.

Além disso, Gimenez (2015) recomenda que seja preciso considerar não somente o aluno e a família, mas todo um sistema que fora construído através dos anos. Esse ponto de vista traz à tona uma questão muito importante sobre o rumo que a educação no país tomou através dos anos.

Se por um lado a educação está mais acessível, seja o ensino básico, o ensino superior, por outro lado, percebe-se que algumas etapas nesse percurso são atropeladas, devido ao aluno, devido aos professores e inclusive devido à incapacidade que algumas instituições possuem por falhar na hora de avaliar um aluno.

Compreendem-se as perspectivas de atuação como um amplo conjunto de esforços em que existem contextos construídos ao longo do tempo, vivências e possibilidades concretas de intervenção. Apesar disso, é 
preciso levar em conta que há ambientes que não conseguem progredir devido falta de investimento, descaso político e falta de políticas públicas locais, prejudicanto todo um sistema (POZZOBON; MAHENDRA; MARIN, 2017).

\section{RESULTADOS E DISCUSSÃO}

O método de revisão narrativa da literatura é eficiente por possibilitar estudos completos sem a necessidade de esgotar as fontes de buscas. Logo após o levantamento bibliográfico da temática, através das palavras-chave, houve a leitura dos resumos das pesquisas que deveriam responder aos seguintes questionamentos: "É possível, com os recursos e meios atuais, utilizar a psicologia na educação?" e "Que tipo de estratégias didáticas podem ser aplicadas em dificuldades de aprendizagem?".

Esses questionamentos foram frequentes dentro das discussões sobre as temáticas. Foi identificada uma ampla discussão em relação às dificuldades de aprendizagem e transtornos de aprendizagem, ao mesmo tempo, uma dificuldade por parte dos profissionais da educação ao compreender e lidar esse fenômeno, sendo unânime a preocupação "demanda-formação".

Foi constatado que o termo dificuldades de aprendizagem ainda é confundido com transtornos ou distúrbios de aprendizagem, por parte de alguns profissionais da educação, em especial, os professores. A falta desse entendimento gera estigmas, quando algum aluno apresenta essas dificuldades.

Observou-se uma grande quantidade de estudos desenvolvidos na região Nordeste do Brasil. Esses temas foram discutidos em monografias e trabalhos de conclusão de curso, mostrando o interesse por essa região ao levantar essas temáticas. Curiosamente, o Ministério da Educação - MEC (2018) afirma que ao longo dos últimos 10 anos, os estados do nordeste, em especial, o Ceará, superou o Indice de Desenvolvimento da Educação Básica - Ideb.

O MEC ainda informa que há grande investimento em educação na região e que entre 2004 e 2014 houve uma grande redução nos índices de 
analfabetismo, caindo de $22,4 \%$ para $16,6 \%$ de toda sua população, no entanto, ainda é a região com o maior número de analfabetos.

Esse número é grande entre pessoas com mais de 60 anos, apesar de que existem programas que buscam resgatar essa população. A taxa de alfabetização aumentou, e segundo estudos, na educação básica as mulheres estudam, em média, 8 anos, enquanto os homens estudam por volta de 7,5 anos.

Com base na análise da literatura levantada, buscamos estabelecer estratégias e dificuldades, resultando em uma tabela que demonstra de forma mais clara o que pode utilizado em algumas das estratégias didáticas.

Tabela 1. Aplicação das estratégias didáticas

\begin{tabular}{|c|c|}
\hline ESTRATÉGIA DIDÁTICA & RECOMENDADO PARA: \\
\hline $\begin{array}{l}\text { Organização temática } \\
\text { do ambiente, atividades fora da sala de aula. }\end{array}$ & $\begin{array}{l}\text { Leitura nos anos iniciais } \\
\text { Dislexia }\end{array}$ \\
\hline $\begin{array}{l}\text { Dicas de organização, reforço nos acertos, } \\
\text { utilização de linguagem clara e voltada para a idade } \\
\text { dos alunos. }\end{array}$ & $\begin{array}{l}\text { Dislexia, } \\
\text { dificuldade dislalia, } \\
\text { aquisição de novas palavras }\end{array}$ \\
\hline $\begin{array}{l}\text { Reforço contínuo nas atividades e nos } \\
\text { comportamentos adequados. }\end{array}$ & $\begin{array}{l}\text { Todas as dificuldades } \\
\text { e transtornos/distúrbios }\end{array}$ \\
\hline $\begin{array}{l}\text { Encaminhamento à rede de assistência, de iniciativa } \\
\text { pública ou privada. }\end{array}$ & $\begin{array}{l}\text { Todas as dificuldades de } \\
\text { aprendizagem } \\
\text { e eventuais necessidades de } \\
\text { acompanhamento profissional }\end{array}$ \\
\hline Uso de lápis, canetas e pinceis e giz. & Disgrafia \\
\hline Construção de maquetes ou outras tarefas em grupo. & $\begin{array}{l}\text { Todas as dificuldades de } \\
\text { aprendizagem } \\
\text { e eventuais necessidades de } \\
\text { interação entre os alunos }\end{array}$ \\
\hline Uso de jogos físicos e virtuais. & Discalculia, dislexia \\
\hline $\begin{array}{l}\text { Dramatização, } \\
\text { Role-Play - Desempenho de papéis. }\end{array}$ & $\begin{array}{l}\text { Todas as dificuldades } \\
\text { e transtornos/distúrbios }\end{array}$ \\
\hline
\end{tabular}

Fonte: Os autores (2018).

Como visto na tabela acima, é possível adequar estratégias dependendo do contexto escolar, e de acordo com as possibilidades que a escola oferecer, trata-se de materiais não muito complexos, fazendo com que seu uso não requeira profissionais específicos para atuar diante de dificuldades ou transtornos. 
Essas estratégias mencionadas na tabela 1 podem ser feitas diariamente ou em dias estratégicos da semana, de forma que haja participação de alunos sem as dificuldades, para não haver segregação ou estímulos negativos.

Através do exposto foi possível perceber que as dificuldades de aprendizagem, mesmo as que são causadas devido a transtornos de aprendizagem podem ser trabalhadas, regularmente, através de estratégias didáticas e de intervenção, e quando necessário, junto a outros profissionais.

Para melhor representar esse dado a figura 1 estabelece um esquema simples onde se pode visualizar o possível desfecho desses fatores, quando trabalhados assertivamente pelo professor, equipe escolar e os demais profissionais.

Figura 1. Desfecho do uso de estratégias didáticas e de intervenção

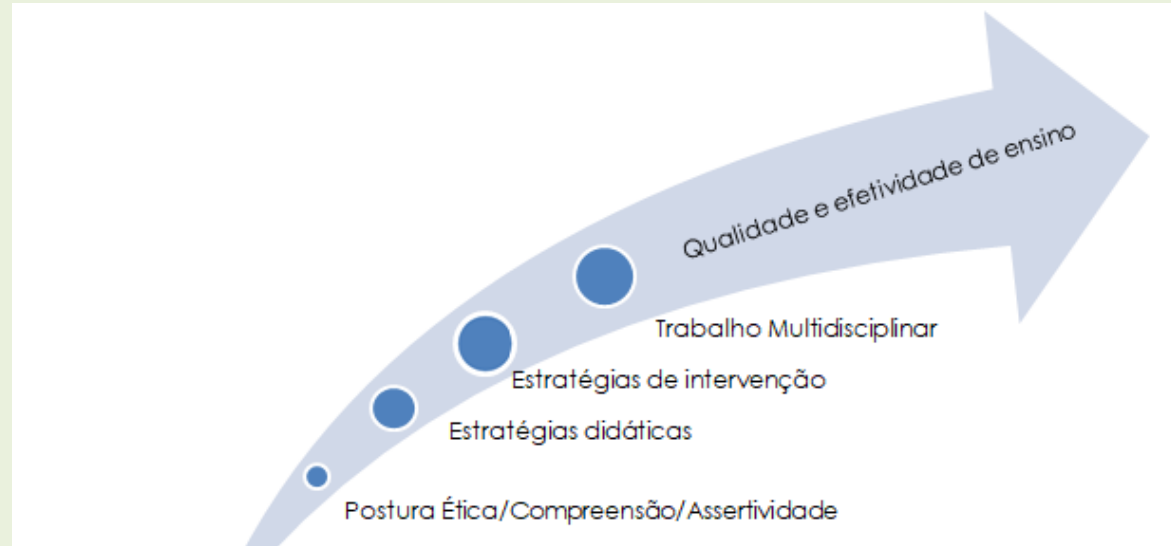

Dificuldades/Transtornos/Distúrbios de aprendizagem

Fonte: Os autores (2018).

A tabela 2 a seguir estabelece alguns fatores que provocam dificuldades de aprendizagem e sugere profissionais que podem intervir e auxiliar. Todos esses profissionais podem ser encontrados no Primeiro, Segundo e Terceiro setor. 
Tabela 2. Estratégias de intervenção (encaminhamentos), baseadas nas dificuldades

\begin{tabular}{|l|l|}
\hline \multicolumn{1}{|c|}{ DIFICULDADES NA APRENDIZAGEM } & \multicolumn{1}{|c|}{ ENCAMINHAMENTO } \\
\hline $\begin{array}{l}\text { Leitura; pronúncia incorreta de palavras (recorrente } \\
\text { e/ou sem evolução); velocidade irregular da fala; } \\
\text { vícios excessivos de linguagem; Disfemia; Entonação } \\
\text { da voz. }\end{array}$ & $\begin{array}{l}\text { Pode ser encaminhado a um } \\
\text { serviço fonoaudiológico e/ou } \\
\text { psicológico. }\end{array}$ \\
\hline $\begin{array}{l}\text { Uso incorreto ou dificuldade para segurar de lápis, } \\
\text { pincel, giz, etc. }\end{array}$ & $\begin{array}{l}\text { Equipe Multidisciplinar; Serviço } \\
\text { psicopedagógico; dependendo } \\
\text { da saruação, } \\
\text { fisioterapêutico. }\end{array}$ \\
\hline $\begin{array}{l}\text { Comportamento agressivo, evasivo, dependente, } \\
\text { explicitamente sexualizado. }\end{array}$ & $\begin{array}{l}\text { Serviço psicológico; } \\
\text { Acompanhamento familiar. }\end{array}$ \\
\hline $\begin{array}{l}\text { Dificuldade na coordenação motora; Suspeitas ou } \\
\text { comprovação de deficiências físicas leves/graves que } \\
\text { interferem em aspectos da aprendizagem; Deficiência } \\
\text { na coordenação motora sem a presença visível de } \\
\text { deficiência devido ao não reforço no meio familiar. }\end{array}$ & $\begin{array}{l}\text { Serviço fisioterapêutico; Serviço } \\
\text { Psicopedagógico. }\end{array}$ \\
\hline $\begin{array}{l}\text { Suspeitas/Comprovação de Discalculia ou dificuldades } \\
\text { acentuadas com o raciocínio numérico, matemático e } \\
\text { lógico. }\end{array}$ & $\begin{array}{l}\text { Serviço psicológico com uso de } \\
\text { Neurofeedback; Psicopedagogo; } \\
\text { Neuropsicólogo; } \\
\text { Neuropsicopedagogo. }\end{array}$ \\
\hline
\end{tabular}

Fonte: Dados dos autores (2018).

\section{CONSIDERAÇÕES FINAIS}

As dificuldades de aprendizagem no contexto escolar são temáticas discutidas por profissionais da educação e por profissionais da saúde, que envolve desde psicólogos a acompanhamento médico. No entanto, as pesquisas demonstraram que ainda não existe clareza quanto aos procedimentos adequados para intervenção.

Acredita-se que o número de salas de aula com alunos que tenham dificuldades de aprendizagem ou transtornos específicos seja pequeno, possibilitando o professor a atuar de maneira que haja integração e aprendizagem efetiva dentro dos momentos de aula.

No entanto, sabe-se que não se pode generalizar e visualizar essa realidade a todas as escolas, especialmente, nas da rede pública de ensino. Por esse motivo, recomendamos aos profissionais da educação que busquem sempre realizar treinamentos e cursos específicos para melhor desempenho profissional e para compreender os mecanismos do comportamento, cognição e aprendizagem das crianças, sempre considerando fatores culturais. 
A inter-relação ética envolve fatores necessários que devem ser considerados para melhores qualidades de ensino, ética envolve um bom senso e cuidado, portanto, percebeu-se que o termo "fracasso escolar" continua a ser usado na literatura, conforme o levantado esse termo gera estigma e segregação, sendo eticamente inadequado o seu uso.

É interessante notar que existe uma rede de assistência no âmbito público, como por exemplo, o Centro de Referência da Assistência Social CRAS, que conta com psicólogos e assistentes sociais e que podem promover intervenções na família das crianças que necessitarem, ou encaminhar para outros profissionais que possam contribuir com a escola.

Não há políticas públicas específicas que trabalham frente às dificuldades de aprendizagem, visto que a porcentagem de pessoas atingidas é pequena.

Provavelmente, isso ocorra devido aos levantamentos do Ministério da Educação, que mostram que esses índices não são alarmantes. Mas cabe lembrar que outros fatores como vulnerabilidade, violência, dificuldades visuais, motoras e auditivas presentes nas crianças podem levar às dificuldades de compreensão, reduzido sua capacidade se comparadas a outros alunos e aumentando, consequentemente, os índices de dificuldades de aprendizagem.

Contudo, é possível utilizar a psicologia e saberes da psicologia dentro da educação através os recursos e meios atuais, ainda que isso não seja o ideal. Há uma rede de assistência muito ampla e com muitos recursos.

Com relação às estratégias, elas podem ser adaptadas de acordo com o ambiente e com a realidade dos alunos, podem ser inovadas através da criatividade do professor, o que significa há total liberdade para criar, aprimorar e desenvolver métodos e instrumentos didáticos.

Contudo, ressaltamos aqui a necessidade de estudos complementares que abordem tal temática, e que possam identificar e trazer novas perspectivas, estratégias ou instrumentos que facilitem a aprendizagem. 


\section{REFERÊNCIAS}

ALVES, P. D. Estratégias de ensino para a aquisição do vocabulário na aula de Espanhol Língua Estrangeira. 2017. Relatório (Mestrado em Ensino do Português) - Faculdade de Letras da Universidade do Porto. Disponível: <https://repositorio-aberto.up.pt/bitstream/10216/110142/2/242784.pdf>.

ALVES, R. J. R; NAKANO, T. C. Criatividade em indivíduos com transtornos e dificuldades de aprendizagem: revisão de pesquisas. Revista Quadrimestral da Associação Brasileira de Psicologia Escolar e Educacional, SP. Volume 19, Número 1, Janeiro/Abril de 2015: 87-96. Disponível em:

<http://www.scielo.br/pdf/pee/v19n1/2175-3539-pee-19-01-00087.pdf>.

Acesso em: 01/11/2018.

Grupo Ānima Educação. Manual Revisão Bibliográfica Sistemática Integrativa: A pesquisa baseada em evidências. 2014 . Ánima.

AMLEIDA, R. P; et al. Prevenção e remediação das dificuldades de aprendizagem: adaptação do modelo de resposta à intervenção em uma amostra brasileira. Revista Brasileira de Educação. v. 21 n. 66 jul.-set. 2016. Disponível em: <www.scielo.br/pdf/rbedu/v2ln66/1413-2478-rbedu-21-66$0611 . p d f>$. Acesso em: 01/11/2018.

Assistência Social de Alagoas. Centro de Referência da Assistência Social CRAS. Disponível: <www.assistenciasocial.al.gov.br/programasprojetos/protecao-social-basica-1/cras-paif>. Acesso em: 10/11/2018.

BARBOSA, C. F. F. Dislexia: dificuldades de aprendizagem na escola. 2014. Monografia (Especialização em Educação) - Instituto de Biociências da Universidade Estadual Paulista. Disponível em:

<repositorio.roca.utfpr.edu.br/jspui/bitstream/1/4288/1/MD_EDUMTE_2014_2_1 9.pdf>. Acesso em: 11/11/2018.

BARBOSA, M. B. B. Dificuldades de aprendizagem no contexto escolar: perspectivas para sua compreensão e superação. 2015. Trabalho de Conclusão (Licenciatura em Pedagogia) - Instituto de Biociências da Universidade Estadual Paulista. Disponível em:

<https://repositorio.unesp.br/bitstream/handle/1 1449/128232/000851216.pdf?s equence $=1$ \&isAllowed=y $>$. Acesso em: 11/11/2018.

BENATO, D. T. Família e escola: uma relação de desafios. Os desafios da escola pública paranaense na perspectiva do professor pde - 2014.

Disponível em:

<www.diaadiaeducacao.pr.gov.br/portals/cadernospde/pdebusca/produc oes_pde/2014/2014_unicentro_ped_artigo_dulcemara_terezinha_benato.pdf >. Acesso em: 10/11/2018.

BEZERRA, M. C. L. Dificuldades de aprendizagem e os fatores que influenciam o fracasso escolar. Monografia (Pós-Graduação em Fundamentos da 
Educação) - Universidade Estadual da Paraíba. 2014. Disponível em: <dspace.bc.vepb.edu.br/jspui/bitstream/123456789/5736/1/PDF\%20\%20Maria\%20do\%20Carmo\%20Lima\%20Bezerrra.pdf>. Acesso em 12/11/2018.

BOLSONI-SILVA, A. T.; et al. Contexto escolar: práticas educativas do professor, comportamento e habilidades sociais infantis. Revista Semestral da Associação Brasileira de Psicologia Escolar e Educacional, SP. Volume 17, Número 2, Julho/Dezembro de 2013: 259-269. Disponível em: <www.scielo.br/pdf/pee/v17n2/v17n2a08.pdf>. Acesso em: 12/11/2018.

BRASIL. Dificuldades de aprendizagem atingem cerca de $\mathbf{5 \%}$ da população escolar. 2014. Disponível em: <www.brasil.gov.br/noticias/educacao-eciencia/2014/07/dificuldades-de-aprendizagem-atingem-cerca-de-5-dapopulacao-escolar>. Acesso em: 10/11/2018.

CASTRO, D. F.; TREDEZINI, A. L. M. A importância do jogo/lúdico no processo de ensino-aprendizagem. Perquirere, 11 (1): 166-181, jul. 2014. Disponível em: <perquirere.unipam.edu.br/documents/23456/422843/A+++importância+do+j ogo-lúdico+no+processo+de+ensino-aprendizagem.pdf>. Acesso em: $10 / 11 / 2018$.

COELHO, M. A. Família e dificuldade de aprendizagem: uma leitura psicopedagógica. Trabalho de Conclusão (Psicopedagogia) - Universidade Federal da Paraíba. Disponível em:

<https://repositorio.ufpb.br/jspui/bitstream/123456789/3012/1/MAC02032015. pdf $>$. Acesso em 21/11/2018.

Conselho Federal de Psicologia. Resolução CFP N. 013/2007. Institui a Consolidação das Resoluções relativas ao Título Profissional de Especialista em Psicologia e dispõe sobre normas e procedimentos para seu registro. Disponível em: <https://site.cfp.org.br/wpcontent/uploads/2008/08/Resolucao_CFP_nx_013-2007.pdf>. Acesso em $21 / 11 / 2018$.

\section{BRASIL. CONSTITUIÇÃO DA REPÚBLICA FEDERATIVA DO BRASIL DE 1988.}

Disponível em:

<www.planalto.gov.br/ccivil_03/Constituicao/Constituicao.htm>. Acesso em: 12/11/2018.

CORTIELLA, et al. The State of Learning Disabilities: Facts, Trends and Emerging Issues. National Center for Learning Disabilities, Inc. Third Edition, 2014.

Disponível em: <https://www.ncld.org/wp-content/uploads/2014/1 1/2014State-of-LD.pdf>. Acesso em: 15/11/2018.

DAMASCENO, M. M. S.; GOMES, A. M. A. Transtornos de Aprendizagem na visão dos Professores. Revista de psicologia, Ano 8, No. 23. 2014. Disponível em: 
<https://www.researchgate.net/publication/273496956_Transtornos_de_Apre ndizagem_na_visao_dos_Professores>. Acesso em: 15/11/218.

FATEL, R. S. A afetividade na relação professor/aluno no processo de ensino/aprendizagem na educação infanil e primeiro ano do ensino fundamental. 2016. Monografia (Pedagogia). Disponível em:

<www.ri.unir.br/jspui/bitstream/123456789/1251/1/FATEL\%2c\%20R.\%20S.pdf>. Acesso em: 01/11/2018.

FEIST, J.; FEIST, G, J.; ROBERTS, T. A. Teorias da personalidade. 2015, Edição: 8. AMGH.

FELCHER, C. D. O.; DIAS, L. F.; BIERHALZ, C. D. K. Construindo Maquetes - Uma Estratégia Didática Interdisciplinar no Eixo Geometrias: Espaço e Forma.

Revista Científica em Educação a Distância. V.5, No 2, 2015. Disponível em: <eademfoco.cecierj.edu.br/index.php/Revista/article/view/238/141>. Acesso em: 05/11/2018.

FERDIG, R. E. Design, Utilization, and Analysis of Simulations and Game-Based Educational Worlds. 1st Edition. 361 p. IGI Global, 2013.

FERREIRA, M. D. Problemas de aprendizagem: conceitos, sintomas e tratamento. Monografia (Especialização em Fundamentos da Educação) Universidade Estadual da Paraíba. 2014. Disponível em: <dspace.bc.vepb.edu.br/jspui/bitstream/123456789/4764/1/PDF\%20\%20\%20Maria\%20Domingos\%20Alves\%20Ferreira.pdf>. Acesso em: 15/11/218.

FERRARI, R. C. Compreensão das dificuldades de aprendizagem escolar na perspectiva da teoria histórico cultural: outra possibilidade de análise desse fenômeno. XI Congresso Nacional de Educação, EDUCERE. 2013. Disponível em: <educere.bruc.com.br/arquivo/pdf2013/15131_7055.pdf>. Acesso em: $11 / 11 / 2018$.

FERREIRA, M.; HORTA, I, V. Leitura - Dificuldades de aprendizagem, ensino e estratégias para o desenvolvimento de competências. Da Investigação às Práticas, 5(2), 144 - 154, 2014. Disponível em: <www.scielo.mec.pt/pdf/inp/v5n2/v5n2a09.pdf>. Acesso em: 10/11/2018.

FREITAS, D. F.; SILVA, F. D. E. Relação professor-aluno e a questão da ética. Revista de Pesquisa Interdisciplinar, Cajazeiras, v. 1, Ed. Especial, 92-98, set/dez. de 2016. Disponível em:

$<$ revistas.ufcg.edu.br/cfp/index.php/pesquisainterdisciplinar/article/view/72/5 1>. Acesso em: 05/11/2018.

GIMENEZ, E. H. R. Dificuldade de Aprendizagem ou distúrbio de aprendizagem?. Revista de Educação, 78-83. Disponível em: <pgsskroton.com.br/seer/index.php/educ/article/viewFile/2214/2109>. Acesso em: 12/11/2018. 
GIUSTA, A. S. Concepções de aprendizagem e práticas pedagógicas.

Educação em Revista, Belo Horizonte, v. 29, n. 1, p. 20-36, Mar. 2013.

Disponível em: <http://www.scielo.br/pdf/edur/v29n1/a03v29n1.pdf>. Acesso em: $17 / 11 / 2018$.

GUSSI, S. L. A. Encaminhamento para ações pedagógicas com base nas vozes das pessoas com deficiência. Dissertação (Mestrado em Ensino de Ciências Humanas, Sociais e da Natureza) - Universidade Tecnológica Federal do Paraná. Disponível em:

<repositorio.utfpr.edu.br/jspui/bitstream/1/1651/1/LD_PPGEN_M_Gussi\%2C\%20 Suzi\%20Lane\%20Amadeu_2016.pdf>. Acesso em: 11/11/2018.

INÁCIO, F. F.; OLIVEIRA, K. L.; MARIANO, M. L. S. Estilos intelectuais e estratégias de aprendizagem: percepção de professores do ensino fundamental. Psicologia Escolar e Educacional, SP. Volume 21, Número 3, Setembro/Dezembro de 2017: 447-455. Disponível em:

<www.scielo.br/pdf/pee/v21 n3/2175-3539-pee-21-03-447.pdf>. Acesso em: $11 / 11 / 2018$.

LIRA, V. T. S. B. A importância do psicólogo educacional nas escolas públicas. Monografia (Especialização em Fundamentos da Educação) - Universidade Estadual da Paraíba. 2014. Disponível em:

<dspace.bc.uepb.edu.br/jspui/bitstream/123456789/6327/1/PDF\%20-

\%20Vanderlucia\%20Tomaz\%20de\%20Sousa\%20Brito\%20Lira.pdf>. Acesso em: $15 / 11 / 218$.

Manual diagnóstico e estatístico de transtorno 5. DSM-5. Trad. Maria Inês Corrêa Nascimento; et al.]; revisão técnica: Aristides Volpato Cordioli... [et al.]. - American Psychiatnc Association. Porto Alegre: Artmed, 2014.

MARTURANO, E. M; ELIAS, L. C. S. Família, dificuldades no aprendizado e problemas de comportamento em escolares. Educar em Revista, Curitiba, Brasil, n. 59, p. 123-139, jan./mar. 2016. Disponível em:

<www.scielo.br/pdf/er/n59/1984-0411-er-59-00123.pdf>. Acesso em: $11 / 11 / 2018$.

MATTOS, A. R.; et al. O cuidado na relação professor-aluno e sua potencialidade política. Estudos de Psicologia, 18(2), abril-junho/2013, 369377. Disponível em: <www.scielo.br/pdf/epsic/v18n2/v18n2a24.pdf>. Acesso em: $01 / 11 / 2018$.

MAZZAROTTO, I. H. E. K. Encaminhamentos escolares de crianças com dificuldades na escrita: uma análise da posição adotada pela família.

Revista CEFAC. 2016 Mar-Abr; 18(2): 408-416. Disponível:

$<w W W . s c i e l o . b r / p d f / r c e f a c / v 18 n 2 / 1982-0216-r c e f a c-18-02-00408 . p d f>$. Acesso em: 12/11/2018. 
MAZZIONI, S. As estratégias utilizadas no processo de ensino-aprendizagem: concepções de alunos e professores de ciências contábeis. Revista

Eletrônica de Administração e Turismo - ReAT | vol. 2 - n. 1 - JAN./JUN. 2013. Disponível em:

<https://periodicos.ufpel.edu.br/ojs2/index.php/AT/article/download/1426/23 38>. Acesso em: 17/11/2018.

Ministério da Educação. Região Nordeste. 2018. Disponível em:

<http://portal.mec.gov.br/ultimas-noticias/222-53701 1943/10745-sp1157328567>. Acesso em: 17/11/2018.

MONTEIRO, J. S.; SILVA, D. P. A influência da estrutura escolar no processo de ensino-aprendizagem: uma análise baseada nas experiências do estágio supervisionado em Geografia. Geografia Ensino \& Pesquisa, v. 19, n.3, set./dez. 2015. Disponível em:

<https://periodicos.ufsm.br/geografia/article/viewFile/14315/pdf>. Acesso em: 12/11/2018.

NATEL, M. C.; TARCIA, R. M. L.; SIGULEM, D. A aprendizagem humana: cada pessoa com seu estilo. Revista Psicopedagogia, São Paulo, v. 30, n. 92, p. 142148, 2013. Disponível em:

<http://pepsic.bvsalud.org/pdf/psicoped/v30n92/08.pdf>. Acesso em: $17 / 11 / 2018$.

NUNES, M. R. M.; et al. O professor frente às dificuldades de aprendizagem: Ensino público e ensino privado, realidades distintas? Revista de Psicologia, Fortaleza, v. 4 - n. 1, p. 63-74, jan./jun. 2013. Disponível em: $<$ repositorio.ufc.br/bitstream/riufc/17809/1/2013_art_mrmnunesjatanksmdcost a.pdf>. Acesso em: 11/11/2018.

OLIVEIRA, G, G. Neurociências e os processos educativos: um saber necessário na formação de professores. Educação Unisinos 18(1):13-24, janeiro/abril 2014. Disponível em: <revistas.unisinos.br/index.php/educacao/article/viewFile/edu.2014.181.02/39 87>. Acesso em 01/11/2018.

PAIVA, R. I. D.; SILVA, S. L. A. A importância da didática no processo de ensino e aprendizagem: a prática do professor em foco. Revista Ensino Interdisciplinar, v. 1, n. 1, Julho/2015 UERN, Mossoró, RN. Disponível em: <periodicos.vern.br/index.php/RECEl/article/download/1488/840>. Acesso em: 05/11/2018.

PAPALIA, D. E.; FELDMAN, R. D. Desenvolvimento humano. 2013, Edição: 12. AMGH.

PIMENTEL, L. S.; LARA, I, C, M. Discalculia: o cérebro e as habilidades matemáticas. 2017. Disponível em: 
<repositorio.pucrs.br/dspace/bitstream/10923/1 1591/2/Discalculia_o_cerebro _e_as_habilidades_Matematicas.pdf>. Acesso em: 11/11/2018.

POZZOBON, M.; MAHENDRA, F.; MARIN, A. H. Renomeando o fracasso escolar. Psicologia Escolar e Educacional, SP. Volume 21, Número 3, Setembro/Dezembro de 2017: 387-396. Disponível em: $<w w w . s c i e l o . b r / p d f / p e e / v 21 n 3 / 2175-3539-p e e-21-03-387 . p d f>$. Acesso em: $11 / 11 / 2018$.

REID, R.; Lienemann, T. O.; Hagaman, J. L. Strategy Instruction for Students with Learning Disabilities, Second Edition. The Guilford Press, 308 p. 2013.

REIS, T. R. Dificuldades de Aprendizagem na Infância e o Encaminhamento para Psicoterapia: Um Estudo de Caso. Revista de Psicologia da IMED, 8(2): 208-217, 2016 - ISSN 2175-5027. Disponível em: <https://dialnet.unirioja.es/descarga/articulo/5763208.pdf>. Acesso em: 12/11/2018>. Acesso em: 12/11/2018.

SÁNCHEZ, A. G. La dislalia: un estudio de casos en Educación Primaria. Trabalho de Conclusão(Graduação em Educação) - Universidad de Granada. 2016. Disponível em:

<digibug.ugr.es/bitstream/handle/10481/46271/GUERREROS\%CINCHEZ_ARAN CHA.pdf; jsessionid=872DE65E330C8152160DD1 12B251 AD16? sequence $=1>$. Acesso em: 15/11/218.

SANTOS, G. H. Inclusão e práticas de ensino para alunos com dislexia.

Trabalho de Conclusão (Letras) - Universidade Estadual da Paraíba. 2016. Disponível em:

<dspace.bc.uepb.edu.br/jspui/bitstream/123456789/14445/1/PDF\%20-

\%20Greyce\%20Hellen\%20Santos.pdf>. Acesso em: 15/11/218.

SEMKIW, R. W.; ANSAI, R. B. Dificuldades de aprendizagem no ensino

fundamental: ações e práticas pedagógicas para melhorar o desempenho docente. Os desafios da escola pública paranaense na perspectiva do professor pde. 2014. Disponível em:

$<$ www.diaadiaeducacao.pr.gov.br/portals/cadernospde/pdebusca/produc oes_pde/2014/2014_unespar-

uniaodavitoria_ped_artigo_rosicler_wenglarck.pdf>. Acesso em: 12/11/2018.

SIGNOR, R. Dislexia: uma análise histórica e social. Revista Brasileira de Linguística Aplicada, Belo Horizonte, v. 15, n. 4, p. 971-999. Disponível em: $<$ www.scielo.br/pdf/rbla/v15n4/1984-6398-rbla-15-04-00971.pdf>. Acesso em: $16 / 11 / 218$.

SILVA, E. G. Ensino/ aprendizagem: uma abordagem filosófica. 2014. Trabalho de Conclusão (Curso de Pedagogia) - Universidade Federal Fluminense. Disponível em: 
<https://app.uff.br/riuff/bitstream/1/1505/1/Monografia\%20Elieide\%20.pdf>. Acesso em 10/11/2018.

SILVA F. J. A relação professor / aluno no processo de ensino e aprendizagem nos anos iniciais do ensino fundamental. Relatório (Pedagogia) - Universidade Estadual da Paraíba. 2016b. Disponível em: <https://monografias.ufrn.br/jspui/bitstream/123456789/2783/3/ARelaçãoProf essorAluno_Relatório\%20Científico_2016.pdf>. Acesso em: 15/11/218.

SILVA, G. D. Professor, alunos, mais do que uma relação pedagógica.

Relatório (Mestrado em Ensino) - Escola Superior de Educação e Ciências Sociais. 2016a. Disponível em:

<https://iconline.ipleiria.pt/bitstream/10400.8/2049/1/Tese_Gil\%20Siva.pdf>. Acesso em: 01/11/2018.

SOUZA, A. M. P. Disgrafia: causas e estratégias de correção no ensino/aprendizagem. Monografia (Letras) - Uniersidade de Brasília.

Disponível em:

<bdm.unb.br/bitstream/10483/17172/1/2015_AniuzoMagalhaes_tcc.pdf>. Acesso em: 15/11/218.

TABILE, A. F.; JACOMETO, M. C. D. Fatores influenciadores no processo de aprendizagem: um estudo de caso. Revista Psicopedagogia. 2017; 34(103): 75-86. Disponível em: <pepsic.bvsalud.org/pdf/psicoped/v34n103/08.pdf>. Acesso em: 11/11/2018.

TAMBAQUIM, M. L. M. Transtornos da aprendizagem não-verbal. Revista Psicopedagogia. 2016; 33(102): 358-64. Disponível em: <pepsic.bvsalud.org/pdf/psicoped/v33n102/13.pdf>. Acesso em: 15/11/218.

TEIXEIRA, A. R.; ALLIPRANDINI, P. M. Z. Intervenção no uso de estratégias de aprendizagem diante de dificuldades de aprendizagem. Revista Semestral da Associação Brasileira de Psicologia Escolar e Educacional, SP. Volume 17, Número 2, Julho/Dezembro de 2013: 279-288. Disponível em:

$<w w w . s c i e l o . b r / p d f / p e e / v 17 n 2 / v 17 n 2 a 10 . p d f>$. Acesso em: 21/11/2018.

Recebido em: 23 de novembro de 2018 Aprovado em: 03 de julho de 2019 